\title{
More regulation not the answer for opioids
}

$\mathrm{E}$ fforts to crack down on prescription opioid abuse must not obstruct access for those in pain, urged experts at the Canadian Medical Association (CMA) General Council in Halifax on Aug. 24.

"We must not forget that these are legal products intended for legitimate therapeutic purposes, essential for the alleviation of suffering," CMA President Dr. Chris Simpson said in a news release. He and others urged a new approach that would focus on creating a national surveillance system and bolstering education to help physicians better prescribe the drugs.

Canada is the world's second-largest per capita consumer of opioid painkillers, a class than includes oxycodone and morphine. Facing an increasing number of reports of addiction and death due to opioids over the past two decades, federal and provincial governments have introduced various measures to curb use. Those steps include Ontario's decision in 2012 not to cover a new formulation of oxycodone under its public drug plan, as well as Health Canada's recent proposal to require companies to make slow-release oxycodone more difficult to crush, snort or inject for a quick high.

But speakers at the CMA's education session argued these measures fail to address the bigger problems behind opioid abuse, including a lack of education and resources to help physicians make decisions about prescribing the drugs and limited access to alternative therapies to manage pain, such as physiotherapy and psychotherapy.

The upshot: patients who legitimately need the drugs face greater barriers to access, and those using opioids to get high simply move on to a more readily available agent. "We now need to be concerned that the pendulum has swung a little too far," said Dr. Mary Lynch, one of three speakers and a professor of anesthesia, psychiatry and pharmacology at Dalhousie University in Halifax. "The solution is to get better care for pain and addiction, not to demonize a class of drugs."

Lynch argued that Canada's opioid epidemic must be kept in perspective

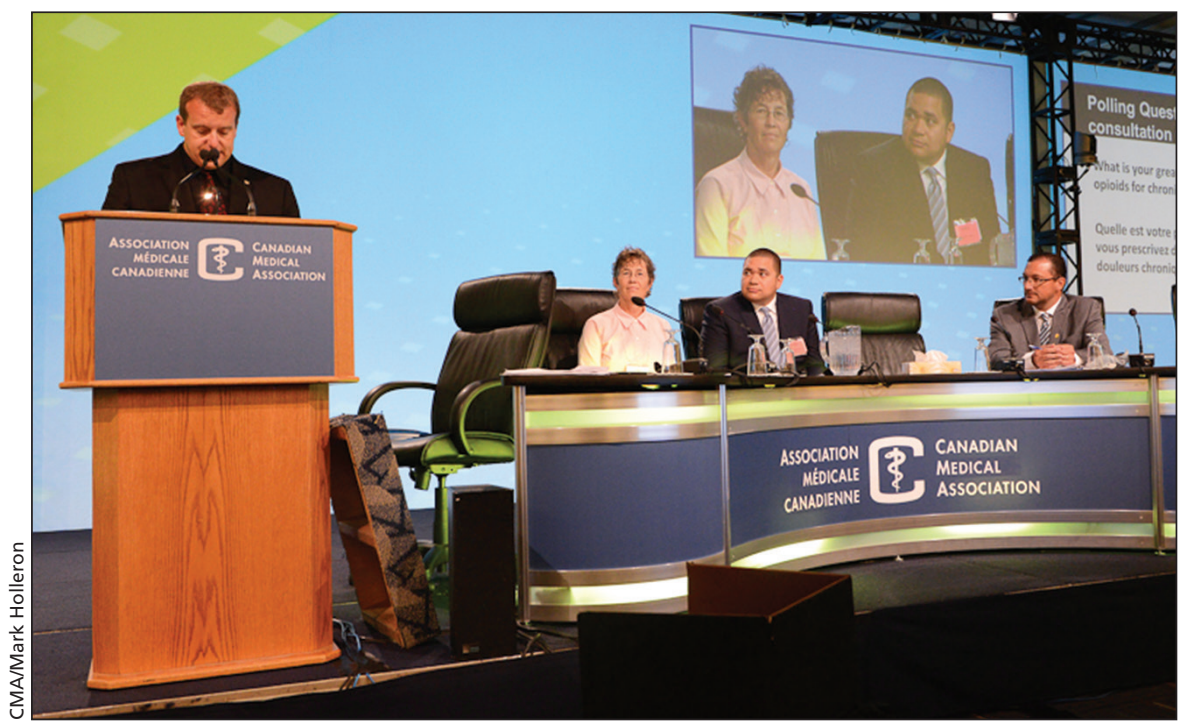

Experts at the CMA General Council are calling for a national pain management strategy that goes beyond police and regulation.

given that the rate of abuse has remained "relatively stable" since 2009 at less than $1 \%$. "So as we develop policies it's important to remember it's a small subpopulation of people when it comes to use to get high or addiction to opioids," she said.

Other experts, however, take issue with Lynch's estimate of the burden of opioid addiction. "The most recent estimates suggest $8 \%$ to $12 \%$ of people on chronic opioid therapy display features suggestive of addiction," Dr. David Juurlink, head of clinical pharmacology and toxicology at the University of Toronto, told CMAJ in a phone interview. "If she wants perspective, the United States Centers for Disease Control estimates that since 1999, 175000 people in the US have died from opioids," he levelled. "Imagine a fully loaded Boeing 747 crashing into a mountain every 10 days."

Moreover, mortality figures don't account for all the other harms those addicted to opioids face. "People who are getting in motor vehicle accidents, falling down stairs, who are unable to fulfill their work obligations or have lifethreatening complications from these drugs," said Juurlink.

Other speakers at the CMA session argued that changing physician prescribing practices will go a long way to reduce these harms.
"What I frequently see is undisciplined, unstructured and arbitrary use of these medications, and most often this approach is applied by a wellintentioned but underinformed physician," said Dr. Douglas Grant, registrar of the College of Physicians and Surgeons of Nova Scotia.

This dearth of information leads to both over- and underprescribing of opioids, he noted. "As soon as some physicians feel the slightest breath of the regulator on their neck, they stop prescribing; they simply abdicate that responsibility."

In some cases, these decisions are also fuelled by unconscious biases, particularly when it comes to First Nations patients, said Dr. Alika Lafontaine, vice-president of the Indigenous Physicians Association of Canada, who was also a featured speaker at the session.

A possible solution may be reporting back to physicians on how their prescribing practices compare to their peers, said Grant. Nova Scotia has seen a "dramatic change" after implementing this approach, according to Grant. He also called for more continuing medical education on opioids. "We are at a point now where we have to consider mandatory CME about prescribing." - Lauren Vogel, CMAJ

CMAJ 2015. DOI:10.1503/cmaj.109-5135 